nos serviços de care são iguais ou um mero prolongamento das funções domésticas. A qualidade do serviço e a do emprego estão intimamente relacionadas, e dependem da profissionalização das pessoas que irão executá-lo (para tornar visíveis e valorizadas as qualificações necessárias) e de políticas públicas próprias, dirigidas a estas e aos velhos: "o bem-estar da pessoa beneficiária do serviço e a garantia de condições de trabalho e de emprego sustentáveis para quem realiza este serviço não podem ser concebidos separadamente" (p. 129).

Claude Dubar, nesses Cadernos de Pesquisa (v. 42, n. 124, maio/ ago. 2012), chamou atenção para o fato de que não é a natureza de uma atividade que a torna "profissional”, mas sua organização, remuneração, reconhecimento social, enfim, sua construção social. Na verdade, o autor questionava a Sociologia das Profissões de cunho funcionalista, para a qual apenas certas atividades seriam verdadeiras profissões - definidas pelo conhecimento formal, abstrato, de nível superior - e, portanto, propiciadoras de realização de si e de reconhecimento pelos outros; as demais seriam apenas ocupações assalariadas comuns. Contrariando tal enfoque, Dubar defende que todo trabalho deve ser formador, fonte de experiências e aprendizagens, de construção de si e de identidade, desde que construído para tanto: “...todos os 'trabalhos', mas também todos os 'trabalhadores', independentemente de gênero, cor ou religião, têm direito à qualificação de 'profissional'. Com a condição de que esses 'trabalhos' sejam organizados, definidos, reconhecidos como 'ofícios', isto é, atividades que requerem competências que possam ser certificadas (p. 364).

Interessante pensar o care sob essa perspectiva que, de algum modo, perpassa todo o livro.

GISELA LOBO B. P. TARTUCE

Socióloga, pesquisadora da Fundação Carlos Chagas gtartuce@fcc.org.br

\title{
A VOZ E A ESCUTA: ENCONTROS E DESENCONTROS ENTRE A TEORIA FEMINISTA E A SOCIOLOGIA CONTEMPORÂNEA
}

MIRIAM ADELMAN

SÃO PAULO: BLUCHER ACADÊMICO, 2009. 246 p.

A obra é uma síntese original e, talvez, uma das poucas em língua portuguesa sobre o assunto. A Voz e a Escuta discute a relação entre sociologia e feminismo, desde a década de 1960, em que a Voz representa as teorias feministas e a Escuta, a audição seletiva da disciplina sobre seus questionamentos. Resultado de doutoramento, a obra é madura e bem construída, devido, em grande parcela, à experiência acumulada da autora. A introdução é de leitura indispensável, pois reconstrói a trajetória 
singular dessa americana, aqui radicada desde a década de 1990, testemunha da introdução dos estudos de gênero na academia, entre Estados Unidos, México e Brasil.

O texto inicia apresentando a gênese histórica e social do feminismo e das "novas formas de pensar" (p. 54, nota 46) que emergem a partir dos anos 1960, com raízes no pós-guerra. Revisa os principais elementos constituintes da “década mítica”, com referências literárias e cinematográficas: a geração beat, na década de 1950, e sua revolta contra o establishment e, posteriormente, o surgimento da Nova Esquerda e da contracultura. Todos esses movimentos, literários, políticos ou sociais, fizeram críticas mais ou menos elaboradas ao modelo cultural dos anos 1950, abrindo oportunidades para o surgimento para "novas formas de pensar”. Um aspecto peculiar dessas novas formas de pensamento é que foram elaboradas a partir de novas trocas entre os grupos sociais, local e globalmente. Essa é a tônica da autora durante todo o texto. Ela mostra como a aproximação e o diálogo com o que, até então, era concebido como "Outro" (o Oriente, o Terceiro Mundo, as mulheres, os negros) reelabora as formas de pensamento.

Enquanto a Nova Esquerda questionava as formas tradicionais de fazer política, considerando valores pós-materiais, a contracultura reelaborava o cotidiano. Em especial na chamada contracultura, há questionamentos embrionários sobre os possíveis lugares das mulheres nos seus projetos, já que a família, a moral sexual convencional e o poder tradicional estavam sendo postos em xeque. A liberalização dos costumes, por vezes, representava em uma armadilha para as mulheres, ao se traduzir na obrigação de sempre estar sexualmente disponíveis para os homens. Esforços de organização autônoma de mulheres surgiram para debater suas questões nos chamados grupos de autoconsciência (consciousness raising groups). Nos movimentos sociais dos anos 1960 e no interior da Nova Esquerda, muitas mulheres começaram a contestar sua posição subalterna.

No campo científico, o surgimento das novas formas de pensar levou a uma mudança de paradigma que repercutiu na epistemologia e na sociologia do conhecimento. Entre elas, desenvolvimentos posteriores das correntes etnográficas da Escola de Chicago (etnometodologia e interacionismo simbólico), as releituras marxistas a partir da psicanálise, as novas problematizações das relações entre estrutura e agência e as insuficiências da centralidade da classe como conceito explicativo, o pós-estruturalismo e a chamada "virada cultural”. Esses desenvolvimentos, com raras exceções, ainda estavam assentados em visões androcêntricas dos novos atores.

Imersa nesse caldo intelectual, a perspectiva feminista começa a introduzir suas críticas, que irão culminar na "emergência e construção da teoria feminista contemporânea” (p. 85). A autora dedica boa parte 
do terceiro capítulo a explicar a ruptura epistemológica provocada pela obra de Simone de Beauvoir. A feminista francesa foi a primeira a chamar a atenção para o profundo viés masculinista dos cânones científicos, isto é, o conhecimento legitimado. Aceitar esse questionamento, portanto, pressupõe a revisão de todo o conhecimento produzido até então. Em face disso, a autora se posiciona de forma cautelosa: não se trata de invalidar o conhecimento até então produzido, mas de revisá-lo a partir da inclusão do que fora antes silenciado. No caso do feminismo, trata-se de introduzir a diversidade da experiência das mulheres, excluídas do processo de formulação das ciências modernas, cuja admissão se deu somente quando suas instituições e epistemes já estavam constituídas. A mais óbvia consequência disso foi a formulação de questões em um mundo social no qual os homens ocupam o espaço público e as mulheres, o privado, bem como a desvalorização do feminino, identificando as mulheres com a natureza, as emoções e o corpo e os homens com a racionalidade. Durante o século XX, porém, essa tendência de exclusão das mulheres foi revertida, e elas passaram a ingressar cada vez mais no ensino superior e no mundo público.

O feminismo, assim como a psicanálise e a teoria pós-moderna, faria parte do que Flax (1991 ${ }^{1}$ apud p. 99) denominou de transitional thinking, um pensamento de transição que rompeu com alguns pontos do pensamento de tradição iluminista, que incluiria uma nova concepção do Eu, corporificado e social, a consideração de gênero como dimensão de análise do social e a revisão de conceitos considerados "clássicos” (como o de trabalho, por exemplo). O desafio posto é, portanto, trabalhar com o conceito de conhecimento/pensamento masculinista que constrói ideias naturalizadas a respeito de gênero a partir de uma série de dicotomias (razão/emoção, natureza/cultura, homem/mulher etc.). Uma nova geração de escritoras e acadêmicas feministas se dedica a compreender o significado da subordinação feminina na releitura de obras clássicas, postura que resultou em desdobramentos a partir das teorias marxistas, da psicanálise e da antropologia.

Para a autora, o impulso crítico do pós-estruturalismo, de forma geral, é que irá contribuir para lançar um dos maiores desafios ao feminismo nos últimos anos: pensar a pluralidade da condição feminina. O problema para o qual chama a atenção é a noção de Mulher Universal, equívoco semelhante e não ocasional ao da ideia masculinista tão criticada de Homem Universal. Foram as feministas negras e as lésbicas que primeiramente apontaram esse equívoco, descontruindo uma experiência universal das mulheres. Esses desafios encontraram obstáculos nas diferentes disciplinas e áreas de conhecimento.

Nesse cenário, a sociologia aparece como a ciência que ficaria in the contemporary West. Berkeley/Los Angeles: University of California Press, 1991 em um "lugar intermediário entre a boa disposição antropológica e a cegueira institucionalizada da história e da literatura” (p. 133). Visto que 
a história e a literatura têm um caráter muito mais interpretativo que a sociologia (em especial, considerando-se a norte-americana), a incorporação de gênero nessas disciplinas exigiria mudanças mais radicais para se criar espaço e voz para as experiências femininas.

A sociologia, por sua vez, incorpora de forma sui generis a perspectiva de gênero: por meio de "mecanismos de contenção", com criação de espaços próprios e a adoção de gênero como mais uma variável descritiva, e não como uma "dimensão que exige profundas reformulações dos conceitos sociológicos mais importantes” (p. 133). A ideia de contenção foi extraída de Stacey e Thorne (1985), ${ }^{2}$ para analisar o contexto americano, mas que a autora acredita que, com as devidas ponderações, é possível aplicar ao contexto brasileiro.

Sendo assim, a sociologia teria tido uma incorporação menos “problemática”, no sentido de pouco alterar as bases tradicionais da disciplina. Mesmo os grandes nomes da sociologia contemporânea no pós68, como Pierre Bourdieu, Alain Touraine, Anthony Giddens e Jürgen Habermas, citados pela autora (p. 134), incorporam, tardiamente e de forma parcial a discussão sobre gênero. Curiosamente, poucas páginas depois, serão analisados, em subseções de tamanhos irregulares para cada autor, Richard Sennet, Giddens, Touraine e Habermas, nessa ordem. Mesmo que se esclareça que a escolha se deu por se tratar de notórios "teóricos da modernidade", a ausência do anteriormente citado Bourdieu se faz sentir por sua considerável atenção a questões de gênero e sua influência nesses estudos.

Adelman procura mostrar que os autores analisados, embora dialoguem em medidas diferentes com o feminismo, não incorporam o gênero de forma importante em suas análises, mesmo quando reformulam categorias extremamente "generificadas", em especial, aquelas que tratam da dicotomia público/privado. Enquanto Sennet e Habermas dialogam menos (ou quase nada) com a teoria feminista, Touraine, que se aproxima um pouco mais, refere-se ao feminismo de forma abstrata, utilizando o movimento de mulheres como exemplo para corroborar sua teoria, pouco citando autoras feministas. Giddens parece fazer um esforço maior para incorporar gênero em suas análises como um aspecto importante e com alguma centralidade. Sua maior lacuna seria a dificuldade de incorporar um aspecto fundamental nas questões de gênero, raça ou classe: a desigualdade.

Apesar das resistências ao gênero nas principais correntes de pensamento da sociologia, conceitos centrais da disciplina sofreram reformulações importantes a partir dos questionamentos suscitados pela sua formulação. Entre eles, trabalho, consumo, público/privado, pessoa, sujeito e ação social. Gênero eleva a um novo patamar temas como consumo e sexualidade, antes negligenciados, mas que são centrais para compreender a cultura da modernidade. A categoria 
trabalho é totalmente rediscutida, incorporando o trabalho não pago e o reprodutivo; a noção de care é introduzida no vocabulário político pelas feministas para valorizar o trabalho do cuidado, quase sempre executado por mulheres.

Uma contribuição importante para a revisão do cânone são os estudos pós-coloniais, que, ao lado das teorias feministas, lançaram novo olhar sobre as sociedades modernas. Autores como Edward Said, Stuart Hall e o precursor Franz Fanon são apresentados. Essa teorização é fundamental para realizar a crítica epistemológica que resultou em uma ampliação do sujeito, seu deslocamento e descentramento, bem como a desconstrução dos binarismos típicos da modernidade (margem/centro, Ocidente/Oriente, tradição/modernidade). A ideia principal dos estudos pós-coloniais é mostrar que a colonização não é algo “externo” às metrópoles, reencenando a História. As relações raciais, nessa reencenação, ganharam novo status e centralidade.

Com inúmeros pontos de contato, as relações entre estudos feministas e pós-coloniais são complexas. Nesses últimos, as questões das mulheres podem ser colocadas em segundo plano, ou instrumentalizadas nas lutas nacionalistas (contra e a favor dessas). Porém, defende a autora, o pós-colonialismo, cujas maiores referências são masculinas (Stuart Hall, Edward Said e Homi Bhabhas) teria diálogos importantes com a teoria feminista. Do outro lado, feministas ocidentais foram criticadas por sustentarem uma visão "orientalista” das mulheres do terceiro mundo, construindo uma "mulher típica”, "vítima”, “pobre, reprimida e submissa às normas e tradições culturais” (p. 213).

Dessas relações emerge uma visão feminista pós-colonial ou multicultural, que dará centralidade ao complexo jogo de relações de classe, raça, gênero, nacionalidade e orientação sexul, na reconstrução das interpretações históricas. Os processos de tradução cultural são úteis para pensar essas trocas culturais entre Oriente-Ocidente e Norte-Sul, mas também para rever esses fluxos, reconhecendo diferentes percursos. Em lugar de somente pensar a imposição de conceitos e ideias do Ocidente (sem negar que isso também pode ocorrer), considera-se possível aproveitar esses conceitos, traduzindo-os e adaptando-os, realizando “empréstimos voluntários” ou apropriações criativas e críticas dos feminismos ocidentais.

As conclusões de Adelman reafirmam a prevalência dos mecanismos de contenção na sociologia; a incorporação de gênero no cânone ainda é muito discreta, o que resulta em alguns problemas importantes. Grandes autores da disciplina dialogaram com a teoria feminista, porém, essas leituras não deixam de ser "interpretações" (muitas vezes, parciais ou incorretas), não corretamente citadas, o que invisibiliza suas contribuições. Portanto, impede-se aos estudantes o acesso direto às autoras feministas e suas discussões. 
O fenômeno da disciplinaridade contribui para a manutenção de temas canônicos. A autora, mais uma vez, contemporiza, defendendo certa manutenção das fronteiras disciplinares. Em lugar de romper fronteiras, defende uma maior "abertura interdisciplinar". Para isso, sugere três "estratégias": 1) um esforço por parte das pesquisadoras feministas de sair dos espaços "confortáveis” da área específica de gênero e se engajar no trabalho de introduzir as teorias feministas no cânone sociológico. A sugestão é que isso seja feito por meio da tradução cultural. No caso brasileiro, o problema da tradução é especialmente importante, pois, sem acesso a materiais em língua portuguesa, a maioria dos estudantes tem acesso apenas às ideias já reinterpretadas pelo cânone; 2) procurar novos interlocutores, frequentando os espaços nos quais são discutidos dos assuntos mais gerais da disciplina; e 3) procurar uma convivência mais intensa com outras áreas disciplinares, para produzir perspectivas mais polifônicas, sem negar a especificidade dos diversos olhares disciplinares e suas contribuições.

O livro de Adelman é importante por resumir diversas influências e referências que constituem o corpus teórico de gênero em seus diversos matizes e correntes teóricas. O peso da literatura de língua inglesa é um viés, mas, por outro lado, devemos lembrar que gênero (ou gender) tem origem nessa língua, daí a importância de compreender o contexto intelectual e histórico de sua criação. A obra se apresenta como uma leitura fundamental para estudantes de diversos níveis que, em contato com estudos de gênero, ainda têm dificuldade de ter acesso às discussões teóricas de fundo sobre o assunto.

\section{ARLENE MARTINEZ RICOLDI}

Socióloga, pesquisadora da Fundação Carlos Chagas

aricoldi@fcc.org.br 